\title{
ERRATUM
}

\section{Erratum to: Seasonal variability of zonal heat advection in the mixed layer of the tropical Pacific*}

\author{
GUAN Cong (官聪) $)^{1,2,3}$, CHEN Yongli (陈永利) $)^{1,2, * *}$, WANG Fan (王凡) $)^{1,2}$ \\ ${ }^{1}$ Institute of Oceanology, Chinese Academy of Sciences, Qingdao 266071, China \\ ${ }^{2}$ Key Laboratory of Ocean Circulation and Waves, Chinese Academy of Sciences, Qingdao 266071, China \\ ${ }^{3}$ University of Chinese Academy of Sciences, Beijing 100049, China \\ (C) Chinese Society for Oceanology and Limnology, Science Press, and Springer-Verlag Berlin Heidelberg 2014 \\ Erratum to: Chinese Journal of Oceanology and Limnology \\ Vol. 31 No. 6, P. 1356-1367, 2013 \\ http://dx.doi.org/10.1007/s00343-014-3019-4
}

The supporting grant information on the footnote of the original version of this article needs to be altered and updated. The new information is given below.

* Supported by the National Basic Research Program of China (973 Program) (No. 2012CB417401) and the CAS Strategic Priority Research Program (No. XDA1101010204)

The online version of the original article can be found at http://dx.doi.org/10.1007/s00343-014-3019-4. 